\title{
产业用纺织先进基础材料进展与对策
}

\author{
蒋金华 ${ }^{1,2}$, 陈南梁 ${ }^{1,2}$, 钱晓明 $^{3}$, 李釒金 ${ }^{4}$, 俞建勇 $^{1}$ \\ (1. 产业用纺织品教育部工程研究中心, 上海 201620；2. 东华大学纺织学院, 上海 201620；3. 天津工业大学 \\ 纺织科学与工程学院，天津 300387； 4. 中国纺织科学研究院有限公司，北京 100025）
}

摘要：纺织产业是我国国民经济的支柱产业，以产业用纺织先进基础材料为主体的纺织材料是我国纺织产业发展的基础和关 键。本文立足材料制造的核心技术，兼顾材料生产、细分行业现状等因素，重点研究产业用纺织先进基础材料领域中量大面 广且为重点需求的 3 类: 非织造纤维材料、纺织结构材料、纺织复合材料。分析了国内外产业用纺织先进基础材料的发展现 状和趋势, 凝练我国在本领域面临的主要问题, 阐述了产业用纺织先进基础材料发展的重点任务与关键技术。研究认为, 加 强产业发展总体规划、实施国家科技创新支撑体系建设、发展一批 “专精特优” 企业并走向国际化, 是产业用纺织先进基础 材料的重点发展举措。

关键词：非织造纤维材料；纺织结构材料；纺织复合材料；研究进展；重点任务

中图分类号：T-9; TD-05; F426 文献标识码：A

\section{Advanced Base Materials for Industrial Textiles: Progress and Countermeasures}

\author{
Jiang Jinhua ${ }^{1,2}$, Chen Nanliang ${ }^{1,2}$, Qian Xiaoming ${ }^{3}$, Li Xin ${ }^{4}$, Yu Jianyong ${ }^{1}$ \\ (1. Engineering Research Center of Technical Textiles, Ministry of Education, Shanghai 201620, China; 2. College of Textiles, \\ Donghua University, Shanghai 201620, China; 3. School of Textile Science and Engineering, Tiangong University,
}

Tianjin 300387, China; 4. China Textile Academy, Beijing 100025, China)

\begin{abstract}
The textile industry is a pillar of China's national economy and advanced base materials for industrial textiles are critical for China's textile industry. In this article, we focus on three types of said materials that are widely demanded by the textile industrynonwoven fiber materials, textile structural materials, and textile composites-considering the key technologies for material manufacturing, material production modes, and industry status. Subsequently, we analyze the development status and trend of the advanced base materials for industrial textiles in China and abroad, summarize the main problems faced by China in this field, and expound the key tasks and core technologies for their development in China. To promote the development of these materials, China should strengthen the overall planning for the industry, improve the national system for supporting science and technology innovation, and foster a group of specialized and excellent enterprises to participate in international competition.
\end{abstract}

Keywords: nonwoven fiber materials; textile structural materials; textile composites; research progress; key tasks

收稿日期 : 2020-08-03; 修回日期 : 2020-09-14

通讯作者: 俞建勇, 东华大学教授, 中国工程院院士, 研究方向为纺织材料开发应用、纺织复合材料和纺织功能材料等;

E-mail: yujy@dhu.edu.cn

资助项目：中国工程院咨询项目 “新材料强国 2035 战略研究” (2018-ZD-03)

本刊网址：www.engineering.org.cn/ch/journal/sscae 


\section{一、前言}

我国进入经济高质量发展阶段，纺织产业正处 于新旧增长模式转换、由大到强发展的关键时期。 面对日益严峻的资源环境问题挑战、世界新工业革 命和新科技革命挑战、战略性新兴产业构建等重大 需求 [1 3], 纺织产业保持可持续发展态势, 从总 量规模领先走向规模、质量、效益和科技水平领先, 确保我国纺织产业的高质量发展和转型升级, 事关 国家经济社会的繁荣稳定。以产业用纺织品为主体 的纺织材料是我国纺织产业发展的基础和关键。

纺织材料产量大、应用面广，主体属于基础 材料。随着市场需求的稳步增长, 我国纺织材料领 域先进基础材料的占比、技术指标和国际竞争力不 断提升 [4]。也要注意到, 我国产业用纺织先进基 础材料尽管已取得显著成就，但面临的问题同样突 出 $[5,6]$ : 通用纤维材料的同质化现象明显, 产品的功 能化和高性能化、绿色化、高品质化亟需提升; 具有 高性能、高功能的新型纺织材料的应用技术缺乏深入 研究，相关标准、技术规范有待建立和完善; 长期以 来缺乏具有重大创新和颠覆性技术性质的新材料产业 化成果; 集成创新能力薄弱, 与产业链结合不紧, 应 用装备的高端化和信息化水平不高。

基于纺织先进基础材料的内涵，本文针对非 织造纤维材料、纺织结构材料、纺织复合材料开 展分析, 梳理当前的重点材料品种, 研判现状和 问题。论述我国产业用纺织先进基础材料的未来 发展重点任务、关键技术以及加强产业发展的规 划建议, 以期为我国纺织产业的材料技术进步提 供理论参考。

\section{二、产业用纺织先进基础材料研究背景}

\section{（一）基本特征}

纺织领域的先进基础材料通常具有以下特征: (1)材料的物理机械性能和品质优良, 如强度、模量、 均匀性、性能稳定性等获得明显提升; (2)在保证物 理机械性能满足应用要求的同时, 通过物理、化学 手段赋予材料新功能, 如通过分子改性、功能粉体 添加改性来赋予材料阻燃或抗菌功能; (3)全生命周 期的绿色化水平提升，如原料来自天然可再生资源 或回收再利用资源的生物基纤维、可控降解的聚乳
酸纤维、低温染色聚酯纤维等; (4)制造过程数字化、 柔性化、智能化, 提升纺织材料差别化 / 功能化的 制造效率和产品品质, 生产过程的能耗、物耗显著 降低, 如基于自动化编织技术的三维结构材料具有 良好的材料性能和品质均一性。

随着产业的发展, 纺织领域研发出的许多关键战 略材料和前沿新材料也逐渐成为新的先进基础材料。

\section{（二）宏观态势}

纺织产业是我国国民经济的支柱产业, 也是重 要的民生产业、具有国际竞争优势的产业。纺织 先进基础材料以化学纤维、产业用纺织品为主体, 成为我国纺织产业发展的基础和关键。2017 年, 我国各类纺织先进基础材料用纤维加工总量为 $5.43 \times 10^{7} \mathrm{t}$, 其中化学纤维产量超过 $4.7 \times 10^{7} \mathrm{t}$ (占全 球化纤产量超过 $70 \%$ ) ; 应用于新能源、航空航天、 医疗卫生、环境保护等各类产业用纺织品占我国纤 维加工量的 $26.9 \%[7,8]$ 。

随着经济社会的发展, 资源枯竭和环境问题 成为越发突出的现实矛盾。这促使纺织产业将纺织 纤维材料确定为重要的基础材料和工程材料, 国 家也将之列入新兴产业发展规划。在纺织先进基础 材料方面, 力求涌现一批具有自主知识产权的原 始创新成果，构建科技成果高效率转化机制，形成 支持产业持久发展的创新能力 [9]; 推动我国重点 领域的中高端产品占比以及纺织材料绿色化、智 能化水平达到国际领先, 引领纺织产业稳定健康发 展 [10 12], 满足全面小康社会建设和战略性新兴 产业发展的重大需求。

\section{（三）主要种类}

基于材料制造的关键核心技术特征，兼顾材料 生产、细分行业现状等因素, 本文将重点研究产业 用纺织先进基础材料中的非织造纤维材料、纺织结 构材料、纺织复合材料 3 类（见表 1 ）。

\section{三、产业用纺织先进基础材料的国内外发展 现状}

\section{（一）国际发展现状}

1. 非织造纤维材料

2012-2017 年北美地区非织造布行业强劲增长 
表 1 产业用纺织先进基础材料的主要种类

\begin{tabular}{|c|c|c|c|}
\hline 名称 & 含义及特点 & 重点品种 & 应用领域 \\
\hline $\begin{array}{l}\text { 非织造 } \\
\text { 纤维材料 }\end{array}$ & $\begin{array}{l}\text { 由纤维直接连接而成的网状多孔纤维介质材 } \\
\text { 料, 是产业用纺织品重点发展的材料类别。 } \\
\text { 基本结构单元是由三维定向或随机排列的纤 } \\
\text { 维组成的网络结构, 依靠纸维之间的摩擦、 } \\
\text { 抱合、缠结、粘合而形成的纤维聚集体材料 }\end{array}$ & $\begin{array}{l}\text { 双组分纺粘水刺非织造材料、高效低 } \\
\text { 阻耐久型驻极非织造空气过滤材料、 } \\
\text { 多模头熔纺复合非织造布、耐高温非 } \\
\text { 织造过滤材料、微纳米纤维复合非织 } \\
\text { 造过滤材料和可冲散湿巾等 }\end{array}$ & $\begin{array}{l}\text { 医疗卫生、环境保护、 } \\
\text { 交通运输、土工建筑、 } \\
\text { 航天航空、农业技术、 } \\
\text { 日常生活等 }\end{array}$ \\
\hline $\begin{array}{l}\text { 纺织结构 } \\
\text { 材料 }\end{array}$ & $\begin{array}{l}\text { 通过纺纱、织造工艺加工而成的纤维聚集排 } \\
\text { 列、相互依存的纤维集合体材料。按照加工 } \\
\text { 技术的不同分为线/绳 / 带类, 机织物 (平纹、 } \\
\text { 斜纹、缎纹、提花), 针织物 (经编、纬编), } \\
\text { 编织物等 }\end{array}$ & $\begin{array}{l}\text { 碳纤维织物、三维编织材料、防刺材料、 } \\
\text { 编织土工材料和高强绳缆等 }\end{array}$ & $\begin{array}{l}\text { 增强结构、人体防护 } \\
\text { 功能结构、智能纺织 } \\
\text { 结构、医用纺织结构、 } \\
\text { 土工结构、高强度线 } \\
\text { 绳 }(\text { 缆 }) / \text { 带等 }\end{array}$ \\
\hline $\begin{array}{l}\text { 纺织复合 } \\
\text { 材料 }\end{array}$ & $\begin{array}{l}\text { 以纺织材料作为结构增强物, 与基体材料复 } \\
\text { 合而成的材料, 分为刚性和柔性两类。前者 } \\
\text { 通常采用高模量纤维等制备而成, 后者至少 } \\
\text { 包括增强结构和涂层结构两部分 [13] }\end{array}$ & 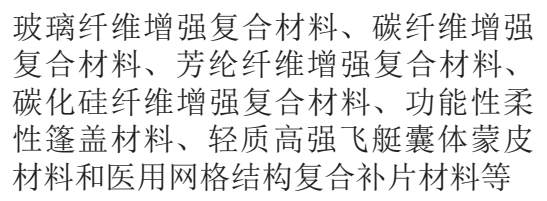 & $\begin{array}{l}\text { 航空航天、汽车、船 } \\
\text { 舶、安全防护、土工 } \\
\text { 建筑、风力发电机叶 } \\
\text { 片、休闲娱乐等 }\end{array}$ \\
\hline
\end{tabular}

(年均增速超过 3.7\%), 预计 2018-2022 年年均增 速将保持在 3.6\% [14]。北美地区新增加了数十条生 产线, 包括针刺、热粘合、纺粘、湿法、水刺等工艺; 非织造工艺得到多样化发展，涉及过滤、交通工具、 吸收性卫生材料、擦拭等多个领域应用。例如，终 端领域的需求规模和增速在不断增加, 吸收性卫生 材料、交通工具用纺织品尤为明显 [14]。

非织造材料生产工艺朝着多种工艺组合生产复 合的方向发展，如双组分、异形截面纺粘技术，复 合纺粘非织造布技术及其与后道工序集成。非织造 设备的发展趋势是大型、高产和高速，单线产量不 断提高, 逐步走向智能化; 设备更加节能节水, 废 弃物的回收和再利用比例逐步提升。非织造材料生 产线朝着组合式、多功能性、差别化的方向发展, 较多采用模块化设计来满足生产线灵活组合的要 求 [15]。

非织造布机械的开发重点有：多种工艺在线复 合成型和混合型非织造装备、微纤等高吸水性材料 的制备装备、弹性非织造布成套生产线、多功能非 织造布添加剂装备及传输系统。提高复合、后整理 等生产线的在线自动化水平与在线检测控制能力, 研发适用特种纤维加工的设备和生产线。

\section{2. 纺织结构材料}

碳纤维布是纺织结构材料中的重点品种之一。 日本东丽公司、英国福瑞斯国际集团、美国 Zoltek 公司、德国西格里集团生产的碳纤维布具有优异的 机械性能, 广泛用于汽车工业、风力发电、航空 航天、机械工程、医疗器械、运动器材和安全防
卫等领域。

三维编织材料涉及以纤维立体织物纺织与成 型为代表的多项先进技术。自 1985 年起，美国国 家航空航天局连续多年实施了先进复合材料技术计 划, 年均经费约 2 亿美元; 其他工业大国也在三维 机织复合材料方面进行了系统研究。功能集成化、 结构功能一体化、低成本快速立体织物成型等是立 体织物技术的发展重点 [16]。

防刺材料获得众多研究，防刺产品研发成为热 点。相关产品有美国杜邦公司的 Kevlar Correctional 型防刺背心、Warwick Mills 公司的 Turtle Skin MFA 防刺服、Criminology 国际公司的防穿透背心、特 拉华大学的机织防刺织物, 法国 Genitex 实验室的 柔软防刺服，英国 Aseo Europe 公司的办公室人员 专用隐蔽式防刺服等。

网格结构土工布主要应用于排水沟、水坝或烟 图过滤, 桥体保护, 铁路结构, 无中间层的海岸保 护，自流水压阻截，垂直地面、沥青公路、倾斜面、 堤岸基层加固等。近年来, 德国研制的特种机台可 以生产多轴结构土工布、新型预定向结构织物等。

高强绳缆较多采用芳香族聚酰胺纤维 (如 Kevlar) 和超高分子量聚乙烯纤维（如 Spectra、 Dyneema), 由多股纱或线捻合而成。20 世纪 90 年 代, Spectra（美国）、Dyneema（荷兰）成功应用 于降落伞制造, 目前在大型吊装、航母绳索、航洋 防护绳网等方面获得广泛应用。

3. 纺织复合材料

刚性结构复合材料的应用领域主要有航空航 
天、风力发电机叶片、汽车、船舶等。例如, 新一 代大型客机（美国波音 787、欧洲空中客车 A350XWB）使用复合材料的比重超过 $50 \%$; 受低风速 陆上风场、海上风场的共同驱动, 风力发电机叶片 的大型化发展趋势尤为明显, 使得先进碳纤维复合 材料的使用量保持了高速增长。

刚性功能复合材料具有性能可设计性, 可通过 不同组分材料的设计来获得具有刚性、功能多样化 的复合材料。德国霍夫公司采用纤维取向技术开发 的车底吸音板, 能够大幅度降低汽车在行驶过程中 的气阻和负面冲击, 已在新一代车型中应用。美国 克尔 - 麦吉公司、佳斯迈威公司, 德国西格里集团、 斯图加特大学也在刚性功能复合材料方面开展了众 多研究工作。

刚性结构 - 功能一体化复合材料用于对材料 承力能力和部分功能均有硬性需求的产品。例如, 碳/碳复合材料是大型固体火箭发动机喉祄、喷管、 扩散段, 飞行器端头帽等的首选材料; 碳/酚醛复 合材料作为重要的耐烧蚀材料应用于高速飞行器, 如载人飞船返回舱、运载火箭壳体、火箭发动机喷 管、再入飞行器保护壳体等; 面临空间复杂环境和 长期服役条件的空间飞行器也普遍采用刚性结构 功能一体化复合材料。

平面膜结构柔性复合材料主要用于建筑膜结 构、篷盖膜材、柔性广告材料等, 早期形式多为涤 纶织物复合材料, 近年来出现了高性能纤维结构柔 性复合材料, 如 Kevlar、热致液晶聚芳酯纤维 ( Vectran)、聚对苯撑苯并二啞唑纤维 ( $\mathrm{PBO}$ ) 等。篷盖 材料是平面膜结构柔性复合材料的主要产品, 目前 国外仍以化纤材料涂覆聚氯乙烯或聚乙烯的涂层篷 盖织物为主; 材料品种多样, 应用发展很快, 市场 比较稳定。

三维充气柔性膜结构材料的典型应用对象是浮 空器囊体蒙皮。目前国外的浮空器蒙皮材料体系已 基本成型, 代表性的研究项目有美国 “高空飞艇” 项目、“传感器与结构集成” 项目、“高空哨兵”项目, 日本的 “平流层平台” 项目; 欧洲、俄罗斯、韩 国、以色列等有关科研机构与企业也开展了研究 工作。在临近空间浮空器蒙皮材料方面, 日本企 业的技术优势明显, 获得美国和欧洲浮空器的较 多应用。

网格结构柔性复合材料主要用于医用补片材
料、组织工程柔性结构等, 且以复合补片形式为主。 补片多为大网孔结构, 有助于组织的长入, 具有较 好的延伸性, 可提高人活动时的舒适感。国外的相 关研究较为成熟, 如 Parietex 复合补片、ProGrip 补 片、Proceed 补片、Vypro II 补片等。美国巴德公司 生产的 3Dmax 补片具有三维结构, 可根据设计尺 寸进行预定型, 在植入体内时无需裁剪, 不需要其 他固定装置。

\section{（二）国内发展现状}

\section{1. 非织造纤维材料}

非织造材料产业在我国的发展历史不长, 但是 发展速度非常快: 1999 年全国产量首次超过日本, 达到 $3.2 \times 10^{5} \mathrm{t} ; 2009$ 年首次超过北美与欧洲, 达 到 $2.409 \times 10^{6} \mathrm{t}$, 位列世界第一。根据统计 $[15,17]$, 2016 年世界非织造布的产量约为 $1.24 \times 10^{7} \mathrm{t}$, 其中 我国非织造布的产量为 $5.354 \times 10^{6} \mathrm{t}$, 约占全球产量 的 $43 \%$, 与欧洲、北美和日本总和的比重相当。作 为名副其实的非织造材料生产大国, 我国在水刺、 针刺、纺粘、熔喷、化学粘合、热粘合、气流成网、 湿法等各种加工方法方面均有涉及, 其中化学粘合 法占比为 49\%、针刺法占比为 $23 \%$ 、水刺法非织造 材料占比为 $10 \%$ (相对比例与美国、欧洲相当)。

按地区看, 我国非织造布生产集中在东部沿海 地区, 产量占全国的 $70.2 \%$, 依然保持了稳定增长; 在中部和西部地区, 湖北的产量达到 $4.08 \times 10^{5} \mathrm{t}$, 河南、四川等地的产量虽然不大但保持了高速增长 势头。我国非织造材料的生产大省有山东 $(21 \%)$ 、 浙江 (19\%)、江苏 $(10 \%)$ 、湖北 (9\%) 和福建 $(8 \%)$, 占全国总产量的 $67 \%$ 。山东的产量优势突出, 一方 面是由于其在土工、防水卷材基布等方面投资迅猛, 使得产能大幅扩张; 另一方面, 山东不少传统纺织 企业转型进入水刺非织造布领域, 使得产能快速增 长。浙江、福建和安徽等省份的非织造布产量年增 长率在 $15 \%$ 左右。

\section{2. 纺织结构材料}

在碳纤维布方面, 我国近几年发展速度较快。 中复神鹰碳纤维有限责任公司是继日本东丽株式会 社、美国赫氏公司之后第 3 个实现高性能干喷湿纺 碳纤维产业化的企业, 具有百吨级 T800 碳纤维的 市场供货能力; 开发的 SYT55 高强中模碳纤维的 性能指标达到国际先进水平, 可替代进口。此外, 
以广州金发碳纤维新材料发展有限公司为代表的一 批企业, 生产的碳纤维和碳纤维织物性能优异、规 格齐全, 广泛用于机械、体育、建筑和航空航天等 领域。

在三维编织材料方面, 我国的研发工作开始于 20 世纪 70 年代, 由南京玻璃纤维研究设计院有限 责任公司率先实施。天津工业大学是国内较早开展 立体编织研究的机构, 2002 年研制出国内首台纬编 双轴向针织设备, 2014 年发展了电子提花控制多层 开口技术、恒张力积极式连续多层送经技术, 成功 研制出国内第一台三维立体机织设备。此外, 以江 苏天鸟高新技术股份有限公司为代表的一批新兴企 业, 补充了立体织物编织的进口设备, 部分实现了 碳纤维复合材料的规模化量产, 产品成功用于铁路 机车配件、飞机刹车预制件等。

在防刺材料方面, 我国的研究工作在 2000 年 前后才启动, 目前初具规模。以北京世祺纤维织造 有限公司为代表的一批企业, 重点生产柔性防刺服, 相关产品集成防割、防刺、反恐、防弹系列功能, 广泛用于民用和军警用人体防护产品。另外, 一些 公司也在开展柔性防刺服的技术研究, 轻型软质防 刺服、防弹防刺服、救生防弹衣等产品填补了国内 军警装备的空白。

在网格结构土工材料方面, 产品市场与国家基 础设施建设密切相关。例如, 2017 年我国铁路行业 新增投资规模为 3560 亿元, 公路建设累计完成固 定资产投资 21162.5 亿元, 落实水利投资 7176 亿元, 加之 “一带一路” 建设的推进, 极大推动了我国土 工与建筑用纺织品行业的快速发展 [17]。

在高强绳缆方面, 诸多领域均开展实际应用。 以扬州巨神绳缆有限公司为代表的一批企业, 作为 国内专业制造化纤缆绳及绳网的优势机构, 实现了 编织结构多股、多层编织的任意设计, 解决了无限 长度编织绳及无限长度无节环形编织等难题。绳网 产品数量有 3000 余种, 各类高端 “绳、网、线、带” 产品广泛用于航空航天、船舶舰艇、海洋工程、安 全防护、消防救援、体育户外、交通运输等领域。

\section{3. 纺织复合材料}

刚性纺织结构复合材料作为先进基础材料、 战略关键材料、前沿新材料, 纳入工业和信息化 部印发的《重点新材料首批次应用示范指导目录
(2017 年版)》的有：碳纤维复合芯导线、汽车用 碳纤维复合材料、风力发电用碳纤维复合材料、航 空制动用碳 / 碳复合材料。在《中国制造 2025》重 点领域技术路线图中与纺织复合材料领域相关的项 目有: 轻量化车身复合材料、高性能碳纤维及其复 合材料、高性能对位芳纶纤维及其复合材料、其他 高性能纤维及其复合材料等。

刚性功能复合材料除常用的碳纤维、玻璃纤维 之外, 还包括在先进飞机、新型船舶、天线罩等产 品上获得广泛应用的芳纶III及其复合材料。我国在 20 世纪 80 年代后期研制了复合材料雷达天线罩、 水雷壳体, 90 年代研制了大型水面船舶用复合材料 桅杆、上层建筑等。与国外相比, 现阶段我国在船 舶复合材料方面的研发与应用仍处于发展阶段, 未 来产业空间较大。

在刚性结构 - 功能一体化复合材料方面, 20 世 纪 80 年代开始, 以南京玻璃纤维研究设计院有限 责任公司、天津工业大学等一批机构为代表, 在国 内开始研发碳纤维复合材料发动机壳体。预制体是 碳/碳复合材料重要的制造环节，支持形成结构刚 性、轻质承载、耐高温隔热、抗烧蚀等功能一体化 的复合材料。

在平面膜结构柔性复合材料方面, 我国的高技 术、高附加值产品还很少, 技术研发能力待补强。 以上海申达科宝新材料有限公司为代表的一批企 业, 具有较好的篷盖布材料生产专业基础水平, 生 产的聚四氟乙烯 (PTFE) 膜材、聚氯乙烯 (PVC) 膜材接近国外先进水平; 但在高端装备用膜材技术 方面存在一定差距, 有关产品应用服役的研究和解 决方案还不够完善。据统计 [8], 2017 年篷盖材料 作为柔性复合材料中的一个大类, 约占我国产业用 纺织品纤维加工量总量的 $16.6 \%$ 。

在三维充气柔性膜结构材料方面, 我国研发 水平较低, 无法高效生产三维大隔距立体织物。 研制超大间距织物高速智能化的专用生产装备迫 在眉睫。

在网格结构柔性复合材料方面, 国内的高端疝 气补片 (疝修补术使用) 还在一定程度上依靠进口。 国产疝气补片的价格与实际使用效果尚可, 目前临 床使用的补片生产企业数量逐渐增加。尽管国产补 片可以满足基础临床应用, 但产品创新力度不够, 
都是使用进口基材再加工而成, 与国际一流水平尚 有差距。

\section{四、我国产业用纺织先进基础材料面临的 问题}

\section{（一）行业共性问题}

产业用纺织先进基础材料行业的知识产权保 护工作有待加强。加强知识产权保护, 使企业在 一定时期内独享知识产权带来的市场利益, 将显 著激发企业的创新热情。但行业目前仍存在违法 成本低、维权成本高等突出矛盾, 在短时间内难 以解决 [18]。

技术创新 “两难” 问题突出。较多企业看重规 模效益, 而忽视了高技术产品的突破; 由于利润下 滑, 难以投入必要资源进行高端产品的研制, 新产 品的开发能力薄弱, 高技术含量产品无法满足市场 需求。

相比于产业的发展速度, 行业的基础研究能力 薄弱, 专业技术和管理人才的培养质量不高, 制约 了行业的健康发展和科技进步。

产业用纺织品的应用领域广泛, 且同类产品在 不同的应用领域具有不同的技术要求。但行业缺乏 标准体系的整体设计 [19], 使得产业用纺织品相关 标准尚未统一、已有标准之间的衔接协调也显不足。

\section{（二）技术与产品方面的问题}

非织造纤维材料面临着国外先进技术的垄断局 面。在宏观政策和强劲内需的拉动下, 我国非织造 过滤产业在过去 10 年里取得长足发展, 但限于行 业起步较晚, 对过滤材料的技术研发工作重视不够; 有关原材料、梯度成型、膜复合、检测、模拟理论 等的研究与国外先进水平差距较大, 因无法自产使 得不少高性能过滤材料依赖进口 [17,19]。在标准体 系和评价体系方面, 相关产品的技术指标和检测方 法标准不统一的问题比较突出, 产品标准与最终产 品的应用标准衔接不畅且产品质量缺乏有效地规范 监管。在产品层面上, 国内企业工艺单一、产品同 质化现象突出。以超纤革为例, 国内企业基本都是 采用不定岛技术 (万华化学集团股份有限公司引进 自日本可乐丽株式会社), 生产工艺的雷同必然带 来产品同质化。
在纺织结构材料方面, 近几年我国碳纤维产业 发展速度较快，但生产设备和生产技术不够先进、 单线产能规模小, 导致生产成本普遍高于进口产品; 国产原丝、碳纤维的品种规格较少, 均匀性和稳定 性较差, 整体性能与进口产品相比存在不小的差距。 我国碳纤维应用技术开发滞后, 碳纤维生产企业与 下游应用脱节, 下游市场亟待培育和拓展。高性能 特种纤维的立体织造设备仍待攻关, 用于大规模商 业化生产的大型三维编织机数量稀缺; 国产三维立 体织物机械的自动化程度不高, 特别是针对复杂异 形立体织物的编织还是以人工辅助的方式进行。我 国防刺织物的防刺类型单一, 开发途径缺少创新, 仍以涂覆、层叠复合、加金属丝/环等传统方式为 主。我国土工材料行业存在重复建设问题, 生产企 业小而散, 达不到经济规模; 材料复合功能研究欠 缺, 较多沿用老工艺、老材料、老技术。

在纺织复合材料方面, 我国在原料、技术、装 备等方面都存在不足。相比该产业先进国家, 有关 专用原材料开发与制备、产业集中度、产品种类和 档次、技术创新等方面都有一定差距。高端纺织品 纤维专用原料主要依靠进口, 原料工程化、产业 化能力较弱, 不能满足产业高质量发展需要 [20]。 纺织柔性材料的基础研究薄弱, 芳纶、聚酰亚胺、 Vectran 等高性能纤维可编织理论及性能表征研究缺 乏体系性, 纺织柔性复合材料增强结构设计理论与 应用机理也因理论欠完备而难以保障产业发展; 有 关纺织柔性复合材料界面理论、多重复合及界面调 控理论研究欠缺, 涂层工艺控制及产业化稳定性技 术相对滞后, 柔性材料的评价体系和标准还不完善。 这些短板使得现有国产材料尚无法满足复杂应用服 役与各类环境的综合要求。此外, 我国纺织柔性复 合材料的加工装备及工艺在自动化、智能化、信息 化方面与世界先进水平存在差距。

\section{五、我国产业用纺织先进材料的重点发展 方向}

\section{（一）技术研究主攻方向}

\section{1. 非织造纤维材料}

重点加强非织造布复合、成型基础理论研究, 加强产品结构和功能设计、界面处理、功能后整 理、产品应用评价和功能检测等关键共性技术研 
究 [17]。推动熔喷、静电纺、熔融共混相分离、闪 蒸纺等新型纳米级非织造, 双组分复合非织造、湿 法成网非织造的技术开发推广，提升涂层、浸渍、 复合等功能整理产业化技术和装备水平，加快纺织 基柔性复合材料开发应用。

开发智能化非织造生产线, 具备在线监测、工 艺问题自动反馈处理、全流程智能管理、可视化操 作等功能。建立过滤、土工、结构增强等领域的产 品应用数据库和分析模型，优化产品工艺设计和制 造流程, 提高产品质量、安全性和使用寿命, 满足 不同应用工况要求 [17]。

推动高效低阻长寿命、有害物质协同治理及功 能化高温滤料和经济可行的废旧滤料回收技术的研 发应用, 发展袋式尘节能降耗应用技术并扩大应用 范围 [17]。加快空气净化器、吸尘器、汽车滤清器 等用途非织造过滤材料的开发应用。推广多功能吸 排水、阻燃高强、智能抗冻抗融、高强抗老化、生 态修复等土工用纺织材料的应用。

\section{2. 纺织结构材料}

在纺织加工装备制造技术方面, 重点研究三维 立体编织、机织、多轴向针织等关键技术和装备, 开发特种产业纤维织造技术和装备。突破纺织结构 柔性材料制备关键技术，扩大在航空航天、建筑、 交通运输等领域中的应用。

在安全防护用编织材料制备技术方面，重点开 展防护机理、防护服系统设计、防护性能测评等研 究, 突破软质防弹防刺防护纺织品及其装备产业化 技术。加快相关产品的开发应用, 如软质防弹防刺 装备、纺织基反恐防暴装备、耐高温防护救援装备、 生化防护装备、家庭用防护灭火装备等。分类开发 应对重大疫情的系列纺织品、智能化消防装备、应 急绳网材料等产品。

在智能纺织结构材料制备技术方面, 重点研 发可穿戴计算与设备结构材料、柔性导电纺织结 构材料, 将微电子与纺织技术融合, 赋予纺织品 智能监护功能, 扩大高附加值智能纺织品的生产 规模。

在医用纺织结构材料制备技术方面，实现植入 型生物医用纺织结构材料的国产化，开发具有自主 知识产权和品牌的医用纺织品, 尤其是高端医用纺 织品。在目前小试的基础上，突破关键技术，建立 中试示范生产线，形成产业化。

\section{3. 纺织复合材料}

在改善复合材料成型技术方面, 重点攻关数控 技术，将机械化、自动化、智能化技术应用到预制 件成型，实现复合材料设计/制造一体化。加强织 物结构设计、新结构力学与几何等理论研究, 开展 传统成型技术的组合创新, 优化产品在三维空间上 的外观轮廓和机械性能。

在优化复合材料生产工艺方面, 掌握液体成型 工艺技术原理，改良复合材料成型工艺，突破热压 预定型、高精度混合注射等技术。加强主承力结构 复合材料研究, 掌握高压 - 树脂传递模塑、压缩 树脂传递模塑、热塑性 - 树脂传递模塑等工艺技术, 实现在汽车车身、飞机壳体、大型船舶等领域的工 程化应用。

在改良复合材料生产装备方面，建立高度集成 化的工艺自动化生产线，掌握一体化装备设计制造 技术。开发数字化、智能化的生产装备和检测装备, 实现复合材料设计/制造一体化、整体成型一体化 能力。

在轻质高强纺织柔性材料结构整体设计技术方 面，根据不同材料类别进行材料创新设计、综合性 能分析、改性优化研究, 解决纺织柔性材料大批量 工业生产中的系列技术问题。研究材料与结构、性 能之间的相互关系, 形成完善的设计理论和制造工 艺体系; 研制配套的成型模具和设备, 建立实际可 用的连接工艺试验检验方法和标准 [20]。

在宽幅多层涂层工艺控制及稳定性技术方面, 攻关多层复合结构及功能杂化涂层技术，突破制约 囊体材料批量生产的关键技术，有效控制涂层内部 和表面缺陷; 改进涂布设备和宽幅多道涂层、烘干、 定型一体化控制及复合成型工艺, 提高涂层工艺及 过程控制的稳定性以满足批量生产要求。

研制超大宽隔距（300 mm 以上）三维立体间 隔织物的智能化成套装备。开发超专用成套装备, 突破智能控制超大隔距梳栉平移控制、智能摆幅控 制、智能化实时动态控制张力补偿、智能电子横移 等技术，实现超大宽隔距的送经、编织、牵拉、卷 取的恒张力和高精度控制。

\section{（二）产品研制重点方向}

经综合研判, 我国纺织领域产业用纺织先进基 础材料的总体发展目标为: 建设布局合理、充满活 
力的产业技术创新体系, 形成一批具有自主知识产 权的原始创新成果, 提升产业持续创新能力; 在非 织造纤维材料、纺织结构材料、纺织复合材料等高 端产业用纺织品等重点方向, 培育具有国际竞争力 的骨干企业和一批 “专精特优” 企业, 补强产业基 础和产业链短板, 显著提高我国中高端产品占比; 产业用纺织材料的绿色化、智能化水平达到国际领 先, 带动纺织产业整体进入价值链的中高端。

面向 2025 年、 2035 年的我国产业用纺织先进 基础材料重点产品见表 2 。

\section{六、对策建议}

\section{（一）加强产业发展顶层规划}

建立部际协调工作机制, 做好顶层设计和规划 统筹, 加强对产业用纺织先进基础材料产业发展的 宏观指导和信息引导, 为产业政策、行业规划、重 大工程提供咨询建议, 集中优势资源推动研发、工 程化、产业化与应用。建立结构合理、稳定的高水 平产业发展战略研究队伍, 通过持续、深入、系统 地研究, 对产业发展状况和规划实施情况进行跟踪 与评估。及时调整、持续完善规划, 为我国相关产 业的宏观决策, 以及为生产企业、金融投资机构、

表 2 我国产业用纺织先进基础材料重点产品

\begin{tabular}{lc}
\hline 种类 & 重点产品名称 \\
\hline 非织造 & 双组分纺粘非织造材料 \\
纤维材料 & 高效低阻耐久型驻极非织造空气过滤材料 \\
& 多模头熔纺复合非织造布 \\
& 耐高温非织造过滤材料 \\
& 微纳米纤维复合非织造过滤材料 \\
纺织结构 & 可冲散湿巾 \\
材料 & 三碳纤维布 \\
& 三维编织材料 \\
& 防刺材料 \\
网格结构土工材料 \\
纺织复合 \\
材料 \\
㐭强绳缆 \\
芳纶纤维增强复合材料 \\
碳化硅纤维增强复合材料 \\
功能性柔性篷盖材料 \\
轻质飞艇囊体蒙皮及充气结构材料 \\
医用网格结构复合补片材料 \\
\hline
\end{tabular}

科研机构的业务活动提供可靠指导。

\section{（二）加强国家科技创新支撑体系建设}

整合高端科技资源, 优化创新运行机制, 组建 国家级纺织材料创新中心, 力求根本性解决以下问 题: 创新资源同质化、碎片化, 关乎产业长远发展 和国际竞争的基础性、公益性研究薄弱, “杀手锏” 型产业重大关键技术创新效率低, 纺织产业价值链 和价值网络缺乏核心枢纽 [21]。着重提升军民两用 关键材料的技术水平和产业能力, 完善重点实验室 和工程技术中心布局, 为原始创新奠定坚实基础。 发挥政府资金的引导作用, 完善政策措施, 吸引风 险基金和产业基金, 共同保障关键技术领域的创新 投入。

\section{（三）发展一批 “专精特优” 企业}

鼓励相关企业做优做强, 开展企业技术和管理 创新, 支持行业 “专精特优” 企业延伸产业链。关 注关键基础材料、核心基础零部件 (元器件)、先 进基础工艺、产业技术基础领域（“工业四基”)、 补强产业基础和产业链短板, 培育产业的国际竞 争优势, 打造更多标杆企业, 形成一批 “单项冠 军” “隐形冠军” “小巨人” 企业。拓宽国际合作 渠道, 结合 “一带一路” 建设, 促进新材料产业 的人才团队、技术资本、标准专利、管理经验等方 面的深入交流和广泛合作。

\section{参考文献}

[1] 刘保林. 国家发展和改革委员会指导的《战略性新兴产业发展 高峰论坛》在北京召开 [J]. 中国产经, 2017, 198(7): 40-42.

Liu B L. The forum on the development of strategic emerging industries, under the guidance of the National Development and Reform Commission, was held in Beijing [J]. Chinese Industry \& Economy, 2017, 198(7): 40-42.

[2] 国家信息中心. “十三五” 以来战略性新兴产业发展形势分析 [R]. 北京: 国家信息中心, 2018.

State Information Center. Analysis on the development situation of strategic emerging industries since the 13th Five-Year Plan [R]. Beijing: State Information Center, 2018.

[3] 纺织服装周刊编辑部. 中国纺织工业典范企业看过来 “强国之 栋”一一国纺织工业领先典范系列大型报道启动 [J]. 纺织服 装周刊, 2015 (28): 14-15.

Editorial Department of Textile Apparel Weekly. China's textile industry model enterprises look at "To build a strong country"China textile industry leading model series of large-scale reports [J]. Textile Apparel Weekly, 2015 (28): 14-15. 
[4] 张振翼, 张立艺, 武玛璠. 我国战略性新兴产业发展环境变化及 策略研究 [J]. 中国工程科学, 2020, 22(2): 15-21.

Zhang Z Y, Zhang L Y, Wu Y F. Environmental changes and strategies for the development of China's strategic emerging industries [J]. Strategic Study of CAE, 2020, 22(2): 15-21.

[5] 姚穆. 纺织产业智能化的发展现状与展望 [J]. 棉纺织技术, 2016, 44(2): 8-10.

Yao M. The current situation and prospect of the intellectualization of textile industry [J]. Cotton Textile Technology, 2016, 44(2): $8-10$.

[6] 古依莎娜, 吴海华, 朱晓光, 等. 我国民生装备优化升级路径及 对策研究 [J]. 中国工程科学, 2020, 22(2): 22-28.

Gu Y S N, Wu H H, Zhu X G, et al. Path and countermeasures of optimizing and upgrading livelihood equipment in China [J]. Strategic Study of CAE, 2020, 22(2): 22-28.

[7] 中国化纤工业协会. 2017年世界主要纤维产量及发展动向 [EB/ OL]. (2018-02-12)[2020-04-30]. https://www.tnc.com.cn/info/ c-001001-d-3639973.html.

China Chemical Fiber Association. 2017 world main fiber output and development trend [EB/OL]. (2018-02-12) [2020-04-30]. https://www.tnc.com.cn/info/c-001001-d-3639973.html.

[8] 中国产业用纺织品行业协会. 2017年中国产业用纺织品行业 运行分析 [EB/OL]. (2018-04-09)[2020-04-30]. http://www.cnita. org.cn/ch/newsdetail.aspx?ids=23_2452.

China Nonwovens \& Industrial Textiles Association. 2017 operation analysis of China's industrial textiles industry [EB/OL]. (201804-09) [2020-04-30]. http://www.cnita.org.cn/ch/newsdetail. aspx?ids $=23 \_2452$.

[9] 孙明贵, 赵晓康. 纺织服装工程科技人才现状与培养模式的改 革 [J]. 中国工程科学, 2010, 12(9): 39-45.

Sun M G, Zhao X K. Technical talent status and educational mode reform of textile and apparel engineering [J]. Strategic Study of CAE, 2010, 12(9): 39-45.

[10] 朱爱萍, 朱曰春. 论纺织产业的智能化发展与前景展望 [J]. 科 技经济导刊, 2019, 27(14): 127.

Zhu A P, Zhu Y C. Intellectualized development and prospect of textile industry [J]. Technology and Economic Guide, 2019, 27(14): 127.

[11] 梁智昊, 许守任. “十三五”新一代信息技术产业发展策略研究 [J]. 中国工程科学, 2016, 18(4): 32-37.

Liang Z H, Xu S R. Study on the development strategy for the new generation of information technology industry during the 13th Five-Year Plan [J]. Strategic Study of CAE, 2016, 18(4): 32-37.

[12] 杜伟伟. 供给侧结构性改革背景下中国纺织业绿色发展研究 [D]. 石河子: 石河子大学(博士学位论文), 2019.

Du W W. Study on green development of China's textile industry under the background of the supply-side structural reform [D]. Shihezi: Shihezi University(Doctoral dissertation), 2019.
[13] 王荣国, 武卫莉, 谷万里. 复合材料概论 [M]. 哈尔滨: 哈尔滨工 业大学出版社, 2015.

Wang R G, Wu W L, Gu W L. Introduction of composite materials [M]. Harbin: Harbin Institute of Technology Press, 2015.

[14] 纺织导报. 第七届中国国际非织造布会议: 我们要碰撞出更 多合作火花 [EB/OL]. (2018-09-06)[2020-04-30]. http://www. texleader.com.cn/article/29749.html.

China Textile Leader. The 7th China international nonwovens conference: We need more cooperation sparks [EB/OL]. (2018-0906) [2020-04-30]. http://www.texleader.com.cn/article/29749.html.

[15] 纺织机械. 非织造机械: 向大型、高产、高速发展 [J]. 纺织机械, 2016 (8): 51.

Textile Machinery. Nonwoven machinery: Developing towards large-scale, high-yield and high-speed [J]. Textile Machinery, 2016 (8): 51 .

[16] 林莉. 纤维立体织物的发展与市场 [J]. 江苏科技信息, 2004 (10): 17-18.

Lin L. Development and market of fiber based 3D fabrics [J]. Jiangsu Science \& Technology Information, 2004 (10): 17-18.

[17] 中国造纸学会. 中国造纸年鉴2018 [M]. 北京: 中国轻工业出版 社有限公司, 2018 .

China Technical Association of Paper Industry. China paper yearbook 2018 [M]. Beijing: China Light Industry Press Ltd., 2018

[18］中国工程科技发展战略研究院. 2020中国战略性新兴产业发展 报告 [M]. 北京: 中国科技出版传媒股份有限公司, 2019 .

Chinese Institute of Engineering Development Strategies. China strategic emerging industries development report 2020 [M]. Beijing: China Science Publishing \& Media Ltd., 2019.

[19］中国产业用纺织品行业协会. 《产业用纺织品“十二五”发展规 划》中期业绩综合盘点 [N]. 中国纺织报, 2013-12-24(2).

China Nonwovens \& Industrial Textiles Association. A comprehensive review of the mid-term performance of the 12th Five-Year Development Plan for industrial textiles [N]. China Textile News, 2013-12-24(2).

[20] 田越, 肖尚明. 平流层飞艇囊体材料的发展现状及关键技术 [J]. 合成纤维, 2013, 42(4): 11-15.

Tian Y, Xiao S M. Development status and key technology of stratospheric airship capsule materials [J]. Synthetic Fiber in China, 2013, 42 (4): 11-15.

[21］中华人民共和国国务院. 国务院关于印发“十三五”国家战略性 新兴产业发展规划的通知 [EB/OL]. (2016-11-29)[2020-04-30]. http://www.gov.cn/zhengce/content/2016-12/19/content_5150090. $\mathrm{htm}$.

State Council of the People's Republic of China. State Council's circular on the publication of the national strategic emerging industries development plan for the 13th Five-Year Plan [EB/ OL]. (2016-11-29)[2020-04-30]. http://www.gov.cn/zhengce/ content/2016-12/19/content_5150090.htm. 